\title{
Normal Age-Adjusted Sagittal Spinal Alignment Is Achieved with Surgical Correction in Adolescent Idiopathic Scoliosis
}

\author{
Subaraman Ramchandran, Norah Foster, Akhila Sure, Thomas J. Errico, Aaron J. Buckland \\ Division of Spine Surgery, Department of Orthopaedic Surgery, NYU Hospital for Joint Diseases, New York, NY, USA
}

\section{Study Design: Retrospective analysis.}

Purpose: Our hypothesis is that the surgical correction of adolescent idiopathic scoliosis (AIS) maintains normal sagittal alignment as compared to age-matched normative adolescent population.

Overview of Literature: Sagittal spino-pelvic alignment in AIS has been reported, however, whether corrective spinal fusion surgery re-establishes normal alignment remains unverified.

Methods: Sagittal profiles and spino-pelvic parameters of thirty-eight postsurgical correction AIS patients $\leq 21$ years old without prior fusion from a single institution database were compared to previously published normative age-matched data. Coronal and sagittal measurements including structural coronal Cobb angle, pelvic incidence, pelvic tilt, thoracic kyphosis, lumbar lordosis, sagittal vertical axis, C2-C7 cervical lordosis, C2-C7 sagittal vertical axis, and T1 pelvic angles were measured on standing full-body stereoradiographs using validated software to compare preoperative and 6 months postoperative changes with previously published adolescent norms. A sub-group analysis of patients with type 1 Lenke curves was performed comparing preoperative to postoperative alignment and also comparing this with previously published normative values.

Results: The mean coronal curve of the 38 AIS patients (mean age, $16 \pm 2.2$ years; $76.3 \%$ female) was corrected from $53.6^{\circ}$ to $9.6^{\circ}$ $(80.9 \%, p<0.01)$. None of the thoracic and spino-pelvic sagittal parameters changed significantly after surgery in previously hypo-and normo-kyphotic patients. In hyper-kyphotic patients, thoracic kyphosis decreased $(p=0.003)$ with a reciprocal decrease in lumbar lordosis $(p=0.01)$, thus lowering pelvic incidence-lumbar lordosis mismatch mismatch ( $p=0.009)$. Structural thoracic scoliosis patients had slightly more thoracic kyphosis than age-matched patients at baseline and surgical correction of the coronal plane of their scoliosis preserved normal sagittal alignment postoperatively. A sub-analysis of Lenke curve type 1 patients $(n=24)$ demonstrated no statistically significant changes in the sagittal alignment postoperatively despite adequate coronal correction.

Conclusions: Surgical correction of the coronal plane in AIS patients preserves sagittal and spino-pelvic alignment as compared to age-matched asymptomatic adolescents.

Keywords: Adolescent idiopathic scoliosis; Spinal fusion; Sagittal alignment; Spinal alignment

Received Aug 19, 2016; Revised Feb 8, 2017; Accepted Mar 2, 2017

Corresponding author: Aaron J. Buckland

Division of Spine Surgery, Department of Orthopaedic Surgery, NYU Hospital for Joint Diseases, 306 East 15th Street, New York, NY 10003, USA

Tel: +1-646-794-8640, Fax: +1-646-602-6927, E-mail: Norah.Foster@nyumc.org 


\section{Introduction}

Adolescent idiopathic scoliosis (AIS) is a complex deformity characterized by a three-dimensional deviation of the spinal column involving the coronal, sagittal, and axial planes. Various theories have been postulated regarding the etiology of AIS including genetic, neurological, muscular and connective tissue anomalies, but its definitive cause remains uncertain [1]. Despite the continued investigations into the true patho-anatomy of AIS, with the development of innovative instrumentation techniques, larger surgical correction can be achieved with respect to radiographic and patient-reported outcomes.

Recent spinal deformity literature has highlighted the importance of sagittal alignment, particularly in adult spinal deformity [2-5]. These important concepts have spread into the AIS population resulting in many new studies focusing on sagittal spinal alignment and its impact on patient outcomes [6]. Patients with primary thoracic curve patterns and AIS have peri-apical thoracic hypo-kyphosis that is most marked when measured in the true plane of the deformity $[7,8]$. Several authors have published that this hypo-kyphosis may further worsen with the use of pedicular screw constructs [9-11]. Reduction of thoracic kyphosis (TK) by $5^{\circ}$ to $10^{\circ}$ has been shown to be a predisposing factor for the development of proximal junctional kyphosis [12]. In addition to radiographic and postural deterioration, long-term studies of patients with sagittal malalignment following surgical correction of AIS have poorer patient-reported outcomes [13,14].

Preoperative planning for surgical correction requires an understanding of the normal age-adjusted sagittal alignment parameters, especially in the adolescent population as it constantly changes [15]. Despite the importance of these values, very few studies have reported normative sagittal alignment in the adolescent population [16-19]. One such study performed on a non-scoliotic adolescent population by Vedantam et al. [16] reported that asymptomatic adolescents tend to stand in a greater negative sagittal spinal balance than adults do, despite similar regional and segmental alignments in the thoracic and lumbar spine. They further stated that, unlike adults, the sagittal vertical axis (SVA) in adolescents does not correlate with the segmental lumbar lordosis (LL) but rather with the level of TK apex thus emphasizing the importance of restoring thoracic kyphosis.

The purpose of this study was to evaluate the early post- operative coronal and sagittal alignment changes in patients with AIS undergoing posterior segmental pedicular instrumented fusion and compare these differences with previously published normative data. We hypothesized that with attention to sagittal alignment restoration, the use of segmental pedicular instrumented fusion may still allow adequate sagittal correction can be achieved comparable to previously published normative data.

\section{Materials and Methods}

\section{Data collection}

A retrospective review of patients with AIS undergoing posterior spinal fusion at a single academic center between January 2013 and January 2015 was performed. Patients with AIS were included if they were younger than 21 years of age without any previous spine fusion and if the preoperative and early postoperative (at 6 months) full-length standing radiographs were available. Patients with congenital or dysplastic deformities of the spine were excluded. All patients underwent a set of full-length standing radiographs including standing anteroposterior, standing lateral, and side-bending supine views for classification and preoperative planning purposes. Data extracted from electronic medical records included demographic parameters such as patient's age at time of surgery, gender, and body mass index; surgical parameters including the number of levels fused, estimated blood loss (EBL), operative duration, whether osteotomies were performed; and radiographic parameters described below.

The surgeries were all posterior segmental instrumented fusions using pedicular screw-rod constructs. Both the hypo-kyphotic and hyper-kyphotic curves were corrected using the direct sequential vertebral reduction technique where the first rod placed in a hypo-kyphotic curve was the concave rod while the first rod placed in the hyperkyphotic curve was the convex rod. In hypo-kyphotic spines, placing the rod on the concave side first generates more kyphosis during derotation as it pulls the vertebrae up to the rod, while placement of the convex rod first in a hyper-kyphotic spine prevents addition of further kyphosis [20]. We do not routinely perform peri-apical Ponte osteotomie in our patients. Patients were followed-up at 3 and 6 months postoperatively to determine the early change in the coronal and sagittal alignment. Postoperative spinal alignment was then compared with previously 
published age-adjusted sagittal alignment norms. For this study, we utilized the values reported by Ries et al. [21] on asymptomatic Caucasian adolescents.

The study was approved by the Institutional Review Board of the New York University School of Medicine (IRB no. i15-01304).

\section{Radiographic parameters}

The radiographic parameters measured in the coronal plane were the upper thoracic, mid-thoracic, thoracolumbar and fractional Cobb angles. In the sagittal plane, we measured pelvic parameters: pelvic incidence (PI, angle subtended by the lines joining the center of bicoxofemoral axis to the mid-point of sacral endplate and the line perpendicular to the sacral endplate), pelvic tilt (PT, angle subtended by the lines drawn from the center of bicoxofemoral axis to the mid-point of sacral endplate and a vertical line drawn from this point), LL (angle between the superior endplates of L1 and S1), and pelvic incidencelumbar lordosis mismatch (PI-LL, lumbar lordosis angle subtracted from the pelvic incidence angle); thoracic parameters: TK (angle between the upper endplate of T4 and lower endplate of T12); cervical parameters: cervical lordosis (CL, angle between the lower endplates of C2 and C7), T1 slope-cervical lordosis mismatch and the C2-C7 sagittal vertical axis (the horizontal offset from a plumbline drawn from the center of the $\mathrm{C} 2$ vertebral body and the posterosuperior corner of the C7 vertebra); and global parameters: SVA (the horizontal offset between a plumb line drawn from the center of $\mathrm{C} 7$ and the posterosuperior corner of the S1 endplate) and T1 pelvic angle (TPA, angle formed between the lines drawn from the center of T1 to the center of bicoxofemoral axis and the line drawn from that point to the center of S1 endplate) (Fig. 1).

\section{Statistical analysis}

Preoperative coronal and sagittal parameters were compared with their corresponding early postoperative values using paired t tests. Preoperative and postoperative sagittal plane parameters including TK, LL, PI, PT, and SVA for all the patients with structural thoracic curves were compared with previously published age-matched normative data by Ries et al. [21] using an independent samples $\mathrm{t}$ test. A separate sub-analysis was performed for patients with type 1 Lenke curves comparing their preoperative and postoperative sagittal alignment with previously published age-matched normative data. Mean values are presented as mean \pm standard deviation and $p$-values of $<0.05$ were considered significant. For statistical analysis, the SPSS ver. 17.0 (SPSS Inc., Chicago, IL, USA) was used.
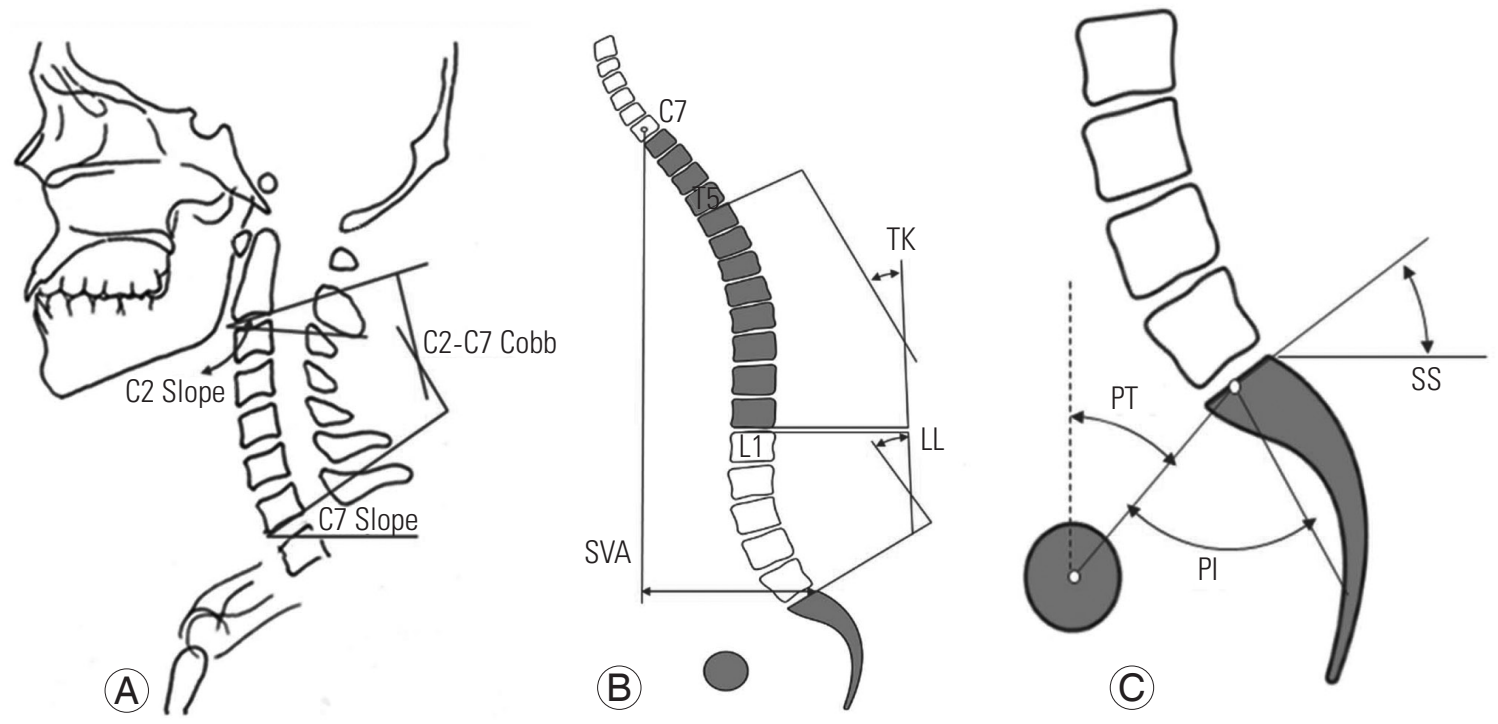

Fig. 1. (A-C) Measurement techniques of sagittal plane parameters. C2 and C7 slopes are calculated by taking the angle between a parallel line from the inferior endplates of $\mathrm{C} 2$ and a horizontal line and a parallel line from the inferior endplate of C7 and the horizontal, respectively. C2-C7, cobb angle from inferior endplate of C2 to inferior endplate of C7; SVA, sagittal vertical axis; TK, thoracic kyphosis; LL, lumbar lordosis; PT, pelvic tilt; PI, pelvic incidence; SS, sacral slope. 


\section{Results}

\section{Stratifying the data}

Thirty-eight AIS patients with a mean age of $16 \pm 2.2$ (range, 8-19 years) met the inclusion criteria out of which 29 patients $(76.3 \%)$ were females. According to the Lenke classification, 24 patients $(63.1 \%)$ had type 1 curves, 6 (15.7\%) had type 3 curves, 3 (7.8\%) had type 5 curves, and $5(13.2 \%)$ had type 6 curves. According to the sagittal modifier criteria, 6 patients $(15.7 \%)$ were hypo-kyphotic, 21 (55.3\%) were normo-kyphotic, and 11 (28.9\%) were hyper-kyphotic. The mean number of levels fused was $9.2 \pm 1.8$ with a mean EBL of $806 \pm 516 \mathrm{~mL}(21.9 \% \pm 14.4 \%$ of estimated blood volume, calculated using average blood volume of $65 \mathrm{~mL} / \mathrm{kg}$ in females and $75 \mathrm{~mL} / \mathrm{kg}$ in males) and mean surgical time of $313 \pm 106$ minutes (range, 120-540 minutes) [22].

The mean preoperative thoracic Cobb angle was $53.6^{\circ} \pm 14.5^{\circ}$ which was corrected to $9.6^{\circ} \pm 6.6^{\circ}$, achieving an $80.9 \%$ correction $(p<0.01)$ and the pre-operative thora- columbar/lumbar Cobb angle was $47.8^{\circ} \pm 11.5^{\circ}$ which was corrected to $9.3^{\circ} \pm 7.5^{\circ}$, correction of $80.5 \%(p<0.001)$.

\section{Sagittal alignment in patients with structural tho- racic curves}

Thirty-five patients had structural thoracic curves with a mean preoperative $\mathrm{TK}$ of $29.8^{\circ} \pm 12.6^{\circ}$. Six of these patients were hypo-kyphotic, 20 were normo-kyphotic, and 9 were hyper-kyphotic. On comparing the preoperative to postoperative change in sagittal alignment in these 3 groups, none of the sagittal parameters were significantly altered in the hypo- and normo-kyphotic groups except T1 slopecervical lordosis mismatch which significantly decreased in the hypo-kyphotic group (Fig. 2). In the hyper-kyphotic group, however, a significant reduction in TK $\left(46.5^{\circ}\right.$ to $\left.36.4^{\circ}, p=0.003\right)$, lumbar lordosis $\left(-67.7^{\circ}\right.$ to $\left.-59.2^{\circ}, p=0.01\right)$ and PI-LL mismatch $\left(-18.9^{\circ}\right.$ to $\left.-10.6^{\circ}, p=0.009\right)$ was observed (Table 1, Fig. 3).

Table 2 shows the comparison between the pre- and postoperative sagittal alignment of patients with structur-
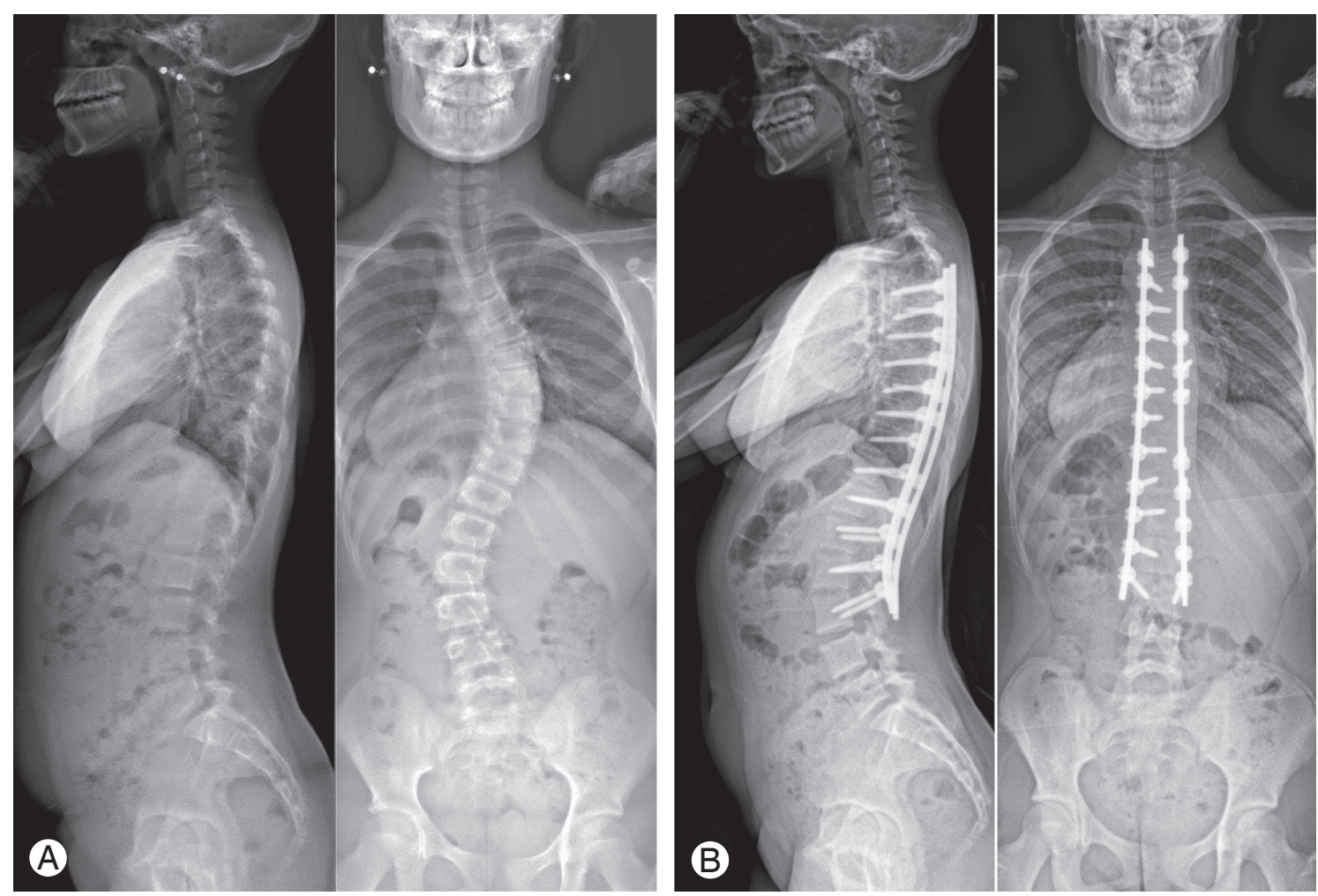

Fig. 2. Representative case from a 15-year-old female who presented with thoracolumbar scoliosis and thoracic hypo-kyphosis (A) and was treated with T4-L3 pedicle-screw construct, achieving normo-kyphosis (B). Her preoperative thoracic coronal curve was $52^{\circ}$ from T3 to L2 and was measured at $12^{\circ} 6$ months postoperatively. Thoracic kyphosis was $18^{\circ}$ at presentation which corrected to $25^{\circ}$ by 6 -month follow-up. Lumbar lordosis changed from $50^{\circ}$ to $61^{\circ}$ after surgery, resulting in $6^{\circ}$ change in pelvic incidencelumbar lordosis mismatch from $1^{\circ}$ to $7^{\circ}$ postoperatively. 
Table 1. Pre- and postoperative sagittal alignment in patients with structural thoracic scoliosis undergoing surgical correction stratified on the basis of preoperative thoracic kyphosis

\begin{tabular}{|c|c|c|c|}
\hline \multirow[b]{2}{*}{ Parameter } & \multicolumn{3}{|c|}{ Baseline thoracic kyphosis (TK) of 35 AIS patients } \\
\hline & $\begin{array}{l}\text { Hypo-kyphosis } \\
\left(\mathrm{TK}<20^{\circ}\right)(\mathrm{n}=6)\end{array}$ & $\begin{array}{l}\text { Normal kyphosis } \\
\left(\text { TK } 20^{\circ}-40^{\circ}\right)(n=20)\end{array}$ & $\begin{array}{l}\text { Hyper-kyphosis } \\
\left(T K>40^{\circ}\right)(n=9)\end{array}$ \\
\hline \multicolumn{4}{|l|}{ Pelvic tilt $\left({ }^{\circ}\right)$} \\
\hline Pre & $13.7 \pm 10.1$ & $12.8 \pm 9.8$ & $5.3 \pm 6.8$ \\
\hline Post & $15.9 \pm 9.9$ & $11.4 \pm 8.8$ & $9 \pm 7.1$ \\
\hline$p$-value & 0.19 & 0.34 & 0.07 \\
\hline \multicolumn{4}{|c|}{ Pelvic incidence $\left({ }^{\circ}\right)$} \\
\hline Pre & $53.4 \pm 11.2$ & $56.6 \pm 11.03$ & $48.8 \pm 15.7$ \\
\hline Post & $53.1 \pm 11.6$ & $54.9 \pm 13.0$ & $49.4 \pm 15.9$ \\
\hline$p$-value & 0.88 & 0.30 & 0.28 \\
\hline \multicolumn{4}{|c|}{ Lumbar lordosis $\left({ }^{\circ}\right)$} \\
\hline Pre & $-52.1 \pm 8.5$ & $-61.2 \pm 12.2$ & $-67.7 \pm 10.8$ \\
\hline Post & $-49.1 \pm 6.5$ & $-60.7 \pm 12.3$ & $-59.2 \pm 11.5$ \\
\hline$p$-value & 0.48 & 0.80 & $0.01^{\text {a) }}$ \\
\hline \multicolumn{4}{|c|}{ Pelvic incidence-lumbar lordosis mismatch $\left({ }^{\circ}\right)$} \\
\hline Pre & $4.4 \pm 10.5$ & $1.3 \pm 31.9$ & $-18.9 \pm 12.4$ \\
\hline Post & $4.5 \pm 14.4$ & $1.7 \pm 30$ & $-10.4 \pm 8.4$ \\
\hline$p$-value & 0.97 & 0.31 & $0.009^{\mathrm{a})}$ \\
\hline \multicolumn{4}{|l|}{$\operatorname{TK}\left({ }^{\circ}\right)$} \\
\hline Pre & $12.5 \pm 3.0$ & $27.5 \pm 6.4$ & $46.5 \pm 4.2$ \\
\hline Post & $17.9 \pm 7.5$ & $28.3 \pm 12.2$ & $36.4 \pm 4.6$ \\
\hline$p$-value & 0.16 & 0.75 & $0.003^{\mathrm{a})}$ \\
\hline \multicolumn{4}{|c|}{ T1 pelvic angle $\left({ }^{\circ}\right)$} \\
\hline Pre & $7.2 \pm 9.1$ & $3.4 \pm 12.8$ & $1 \pm 8.9$ \\
\hline Post & $9.2 \pm 9.8$ & $3.2 \pm 7.7$ & $2.9 \pm 6.9$ \\
\hline$p$-value & 0.23 & 0.91 & 0.16 \\
\hline \multicolumn{4}{|c|}{ Sagittal vertical axis (mm) } \\
\hline Pre & $-6.7 \pm 17.4$ & $29 \pm 6.8$ & $-24.7 \pm 22$ \\
\hline Post & $-11.9 \pm 21.6$ & $15.1 \pm 3.5$ & $-19 \pm 19.3$ \\
\hline$p$-value & 0.65 & 0.25 & 0.33 \\
\hline \multicolumn{4}{|c|}{$\mathrm{C} 2-\mathrm{C} 7 \mathrm{Cobb}$ angle $\left({ }^{\circ}\right)$} \\
\hline Pre & $12.8 \pm 12.9$ & $3.2 \pm 13.5$ & $-7.5 \pm 13.4$ \\
\hline Post & $7.1 \pm 4.8$ & $2.4 \pm 15.3$ & $-8.1 \pm 18.9$ \\
\hline$p$-value & 0.19 & 0.80 & 0.9 \\
\hline \multicolumn{4}{|c|}{ C2-C7 sagittal vertical axis (mm) } \\
\hline Pre & $22.9 \pm 10.2$ & $14.1 \pm 9.7$ & $26.8 \pm 5.7$ \\
\hline Post & $21.5 \pm 7.1$ & $14.9 \pm 10.4$ & $25 \pm 6.6$ \\
\hline$p$-value & 0.70 & 0.73 & 0.28 \\
\hline \multicolumn{4}{|c|}{ T1 slope-cervical lordosis mismatch $\left({ }^{\circ}\right)$} \\
\hline Pre & $27.9 \pm 8.9$ & $20.4 \pm 8.1$ & $19.5 \pm 10.7$ \\
\hline Post & $22.1 \pm 6.5$ & $22.3 \pm 9.3$ & $19.1 \pm 3.1$ \\
\hline$p$-value & $0.03^{\mathrm{a})}$ & 0.45 & 0.86 \\
\hline
\end{tabular}

AIS, adolescent idiopathic scoliosis.

${ }^{\text {a) }} p$-value represents significance. 

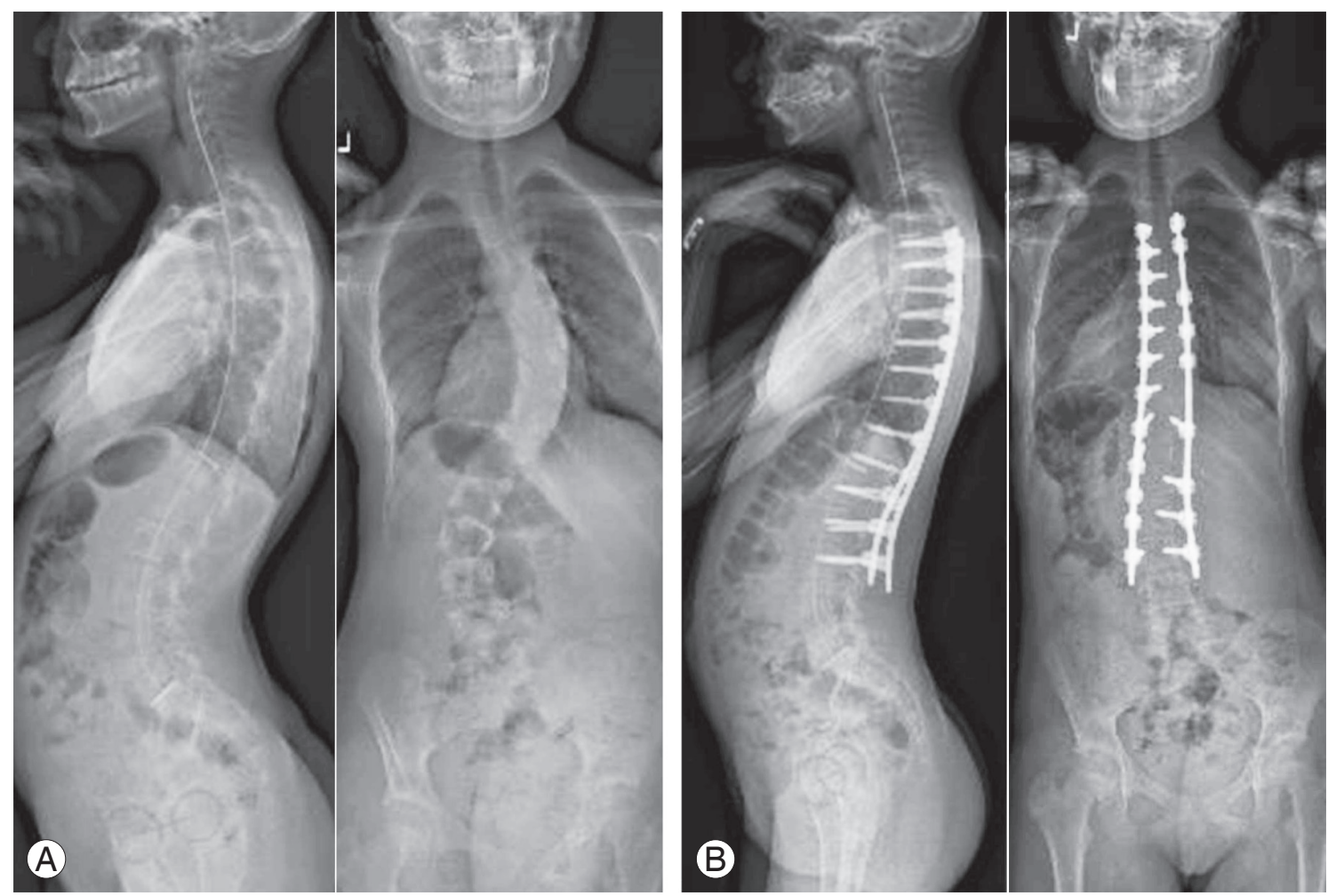

Fig. 3. Representative case from a 16-year-old female who presented with a hyper-kyphotic thoracic curve (A) and was treated with T4-L3 pedicle-screw construct, achieving normo-kyphosis (B). Her preoperative coronal thoracic curve was $49^{\circ}$ from $T 5$ to $\mathrm{L} 2$ and measured $10^{\circ}$ at 6 months postoperatively. Thoracic kyphosis was $62^{\circ}$ at presentation which corrected to $36^{\circ}$ by 6 -month follow-up. Lumbar lordosis changed from $79^{\circ}$ to $62^{\circ}$ after surgery, resulting in $13^{\circ}$ decrease in pelvic incidence-lumbar lordosis mismatch from $34^{\circ}$ to $21^{\circ}$ postoperatively.

Table 2. Comparison of pre- and postoperative sagittal alignment parameters in patients with structural thoracic scoliosis with previously reported age-matched normative values

\begin{tabular}{|c|c|c|c|}
\hline Sagittal parameter & $\begin{array}{l}\text { Patients with structural thoracic scoliosis in our } \\
\text { cohort ( } \mathrm{n}=35 \text {; age, } 16 \pm 2.2 \mathrm{yr} \text { ) }\end{array}$ & $\begin{array}{l}\text { Normative data reported by Ries et al. [21] } \\
\qquad(\mathrm{n}=30 ; \text { age, } 15.5 \mathrm{yr})\end{array}$ & $p$-value \\
\hline \multicolumn{4}{|l|}{ Pelvic incidence $\left({ }^{\circ}\right)$} \\
\hline Preoperative & $54.3 \pm 12.5$ & $48.8 \pm 13.1$ & 0.08 \\
\hline Postoperative & $53.1 \pm 13.4$ & & 0.19 \\
\hline \multicolumn{4}{|c|}{ Sagittal vertical axis (mm) } \\
\hline Preoperative & $-15.7 \pm 25.6$ & $-14.8 \pm 16.1$ & 0.86 \\
\hline Postoperative & $-11.8 \pm 17.4$ & & 0.47 \\
\hline \multicolumn{4}{|l|}{ Pelvic tilt $\left({ }^{\circ}\right)$} \\
\hline Preoperative & $11.4 \pm 9.8$ & $8.9 \pm 9.5$ & 0.30 \\
\hline Postoperative & $11.6 \pm 8.6$ & & 0.23 \\
\hline \multicolumn{4}{|l|}{ Lumbar lordosis $\left({ }^{\circ}\right)$} \\
\hline Preoperative & $-61.3 \pm 11.1$ & $58.2 \pm 11.9$ & 0.30 \\
\hline Postoperative & $-58.3 \pm 11.9$ & & 0.97 \\
\hline \multicolumn{4}{|l|}{ Thoracic kyphosis $\left({ }^{\circ}\right)$} \\
\hline Preoperative & $29.8 \pm 12.6$ & $23.5 \pm 8.5$ & $0.02^{\text {a) }}$ \\
\hline Postoperative & $28.6 \pm 11.5$ & & $0.04^{\text {a) }}$ \\
\hline
\end{tabular}

${ }^{\text {a) }}$-value represent significance. 
al thoracic scoliosis in our cohort and that of previously published data by Ries et al. [21]. Both preoperative and postoperative TK in our cohort were slightly higher compared to age-matched normative values $\left(29.8^{\circ} \pm 12.6^{\circ}\right.$ and $28.6^{\circ} \pm 11.5^{\circ}$ vs. $23.5^{\circ} \pm 8.5^{\circ}, p=0.02$ and $p=0.04$, respective- ly), yet still within the range of normal kyphosis $\left(20^{\circ}-40^{\circ}\right)$. However, the pre- and postoperative PT observed in our patients was found to be similar to the normative data $\left(11.4^{\circ} \pm 9.8^{\circ}\right.$ and $11.6^{\circ} \pm 8.6^{\circ}$ vs. $8.9^{\circ} \pm 9.5^{\circ}, p=0.30$ and $p=0.23$, respectively).

Table 3. Pre- and postoperative alignment changes in patients with Type 1 Lenke curves undergoing surgical correction

\begin{tabular}{|c|c|c|c|}
\hline Parameter & Preoperative $(\mathrm{n}=24)$ & Postoperative $(n=24)$ & $p$-value \\
\hline Main thoracic coronal Cobb angle $\left({ }^{\circ}\right)$ & $51.9 \pm 5.3$ & $8.8 \pm 1.3$ & $0.001^{\mathrm{a})}$ \\
\hline Pelvic incidence $\left({ }^{\circ}\right)$ & $51.2 \pm 13$ & $50.4 \pm 13.8$ & 0.40 \\
\hline Pelvic tilt $\left({ }^{\circ}\right)$ & $8.7 \pm 8.1$ & $10.7 \pm 8.5$ & 0.09 \\
\hline Lumbar lordosis $\left({ }^{\circ}\right)$ & $-60.6 \pm 12.9$ & $-57 \pm 11.4$ & 0.07 \\
\hline Pelvic incidence-lumbar lordosis mismatch $\left({ }^{\circ}\right)$ & $-3.9 \pm 30.8$ & $3.1 \pm 32.5$ & 0.39 \\
\hline $\mathrm{L} 1-\mathrm{L} 4\left(^{\circ}\right)$ & $-25.3 \pm 12.4$ & $-22.4 \pm 10.3$ & 0.18 \\
\hline L4-S1 $\left(^{\circ}\right)$ & $-35.3 \pm 8.1$ & $-35.1 \pm 7.1$ & 0.92 \\
\hline Thoracic kyphosis $\left({ }^{\circ}\right)$ & $31.8 \pm 12.2$ & $32.3 \pm 11.7$ & 0.83 \\
\hline T1 pelvic angle $\left({ }^{\circ}\right)$ & $1.1 \pm 9.4$ & $2.2 \pm 7.2$ & 0.40 \\
\hline Sagittal vertical axis (mm) & $-16.6 \pm 25.6$ & $-15.5 \pm 19.9$ & 0.83 \\
\hline $\mathrm{C} 2-\mathrm{C} 7 \mathrm{Cobb}(\mathrm{CL})\left(^{\circ}\right)$ & $2.9 \pm 14$ & $-0.2 \pm 15.7$ & 0.11 \\
\hline C2-C7 sagittal vertical axis $(\mathrm{mm})$ & $20.8 \pm 9.4$ & $18.5 \pm 10.6$ & 0.16 \\
\hline T1 slope-cervical lordosis mismatch $\left({ }^{\circ}\right)$ & $21.5 \pm 9.1$ & $21 \pm 8.9$ & 0.79 \\
\hline
\end{tabular}

${ }^{a)} p$-value represent significance.

Table 4. Comparison of pre- and postoperative sagittal alignment parameters in patients with Type 1 Lenke curves undergoing surgical correction with previously reported age-matched normative values

\begin{tabular}{|c|c|c|c|}
\hline Sagittal parameter & $\begin{array}{c}\text { Patients with type } 1 \text { Lenke curve in our } \\
\text { cohort ( } \mathrm{n}=24 \text {; age, } 15.8 \pm 2.5 \mathrm{yr} \text { ) }\end{array}$ & $\begin{array}{l}\text { Normative data reported by Ries et al. [21] } \\
\qquad(\mathrm{n}=30 ; \text { age, } 15.5 \mathrm{yr})\end{array}$ & $p$-value \\
\hline \multicolumn{4}{|l|}{ Pelvic incidence $\left({ }^{\circ}\right)$} \\
\hline Preoperative & $51.2 \pm 13$ & $48.8 \pm 13.1$ & 0.51 \\
\hline Postoperative & $50.4 \pm 13.8$ & & 0.67 \\
\hline \multicolumn{4}{|c|}{ Sagittal vertical axis (mm) } \\
\hline Preoperative & $-16.6 \pm 25.6$ & $-14.8 \pm 16.1$ & 0.75 \\
\hline Postoperative & $-15.5 \pm 19.9$ & & 0.89 \\
\hline \multicolumn{4}{|l|}{ Pelvic tilt $\left({ }^{\circ}\right)$} \\
\hline Preoperative & $8.7 \pm 8.1$ & $8.9 \pm 9.5$ & 0.94 \\
\hline Postoperative & $10.7 \pm 8.5$ & & 0.47 \\
\hline \multicolumn{4}{|l|}{ Lumbar lordosis $\left({ }^{\circ}\right)$} \\
\hline Preoperative & $-60.6 \pm 12.9$ & $58.2 \pm 11.9$ & 0.48 \\
\hline Postoperative & $-57 \pm 11.4$ & & 0.71 \\
\hline \multicolumn{4}{|l|}{ Thoracic kyphosis $\left({ }^{\circ}\right)$} \\
\hline Preoperative & $31.8 \pm 12.2$ & $23.5 \pm 8.5$ & $0.005^{\mathrm{a})}$ \\
\hline Postoperative & $32.3 \pm 11.7$ & & $0.002^{\mathrm{a})}$ \\
\hline
\end{tabular}

${ }^{a)} p$-value represent significance. 


\section{Coronal and sagittal alignment in patients with type 1 Lenke curves}

A sub-analysis of the 24 patients with type 1 Lenke curves (12 type 1A, 6 type $1 \mathrm{~B}$, and 6 type $1 \mathrm{C}$ ) demonstrated that the mean preoperative thoracic Cobb angle of $51.9^{\circ} \pm 5.3^{\circ}$ corrected to $8.8^{\circ} \pm 1.3^{\circ}$ postoperatively, a correction of $82.6 \%(p<0.001)$. With regard to sagittal alignment, none of the thoracolumbar nor the spino-pelvic parameters had any significant change ( $p>0.05$ ) (Table 3$)$. TK was the only sagittal parameter that was statistically significant for both the preoperative and postoperative values when compared to those of age-matched asymptomatic patients $\left(31.8^{\circ} \pm 12.2^{\circ}\right.$ and $32.3^{\circ} \pm 11.7^{\circ}$ vs. $23.5^{\circ} \pm 8.5^{\circ}, p=0.005$ and $p=0.002$, respectively) (Table 4 ); however, the patients in our cohort are still within the range of normal kyphosis.

\section{Discussion}

In addition to coronal alignment and derotation, the importance of sagittal alignment correction should also be considered during fusion for AIS patients. Thoracic alignment is often cited as being hypo-kyphotic or even lordotic in many cases of AIS [11,22,23]. A study performed by Pizones et al. [24] analyzed sagittal parameters for AIS patients based on their Lenke curve type and found that in patients with moderate AIS, Lenke type 1 curves exhibited normal thoracic sagittal parameters, whereas type 3 had lower thoracic segmental hypo-kyphosis and type 2 had upper segmental hyper-kyphosis. Sangole et al. [25] even used 3D reconstructions of the spine illustrating that type 1 curves can be broadly divided into normo-kyphotic and hypo-kyphotic group.

Recent research investigating the perioperative changes in TK have been inconsistent. Roussouly et al. [26] not only found a prevalence of lower PI (57\%) and lower TK values than average, but also a significant decrease in TK coupled to a decrease of LL and CL in the normo-kyphotic group after corrective surgery, while TK and CL were improved in the hypo-kyphotic group. Similarly, a study done by Sudo et al. [27] using the simultaneous doublerod rotation technique showed a statistically significant improvement in TK from $11.9^{\circ}$ to $20.5^{\circ}$ after surgery in Lenke type 1 AIS patients in a Japanese population. Conversely, Hilibrand et al. [28] found that TK is preserved in patients treated with Cotrel-Dubousset and Harrington segmental instrumentation in their study intended to as- sess sagittal alignment of the cervical spine in AIS.

When compared to asymptomatic, age-matched patients without spinal deformity, those with AIS in our study had similar sagittal profiles with respect to all studied parameters with the exception of TK. While on average within a normo-kyphotic range of $\mathrm{TK}$, our cohort of patients had slightly more TK than normal controls reported by Ries et al. [21] both preoperatively as well as postoperatively $\left(29.8^{\circ} \pm 12.6^{\circ}\right.$ and $28.6^{\circ} \pm 11.5^{\circ}$ vs. $23.5^{\circ} \pm 8.5^{\circ}, p=0.02$ and $p=0.04$, respectively). The same results were seen on comparison of these controls to our subset of patients with Lenke type 1 curves. This data deviates from the commonly cited thoracic hypo-kyphosis in AIS patients and is in concordance with results of Ries et al. [21] with respect to patients specifically of Lenke type 1 and 2 curve.

However, our results differ with regards to change in the TK after pedicle screw based posterior spinal fusion. Our study demonstrated the statistically significant decrease in TK and reciprocal decrease in the noninstrumented LL reported by Ries et al. [21] was only present in patients that were hyper-kyphotic at baseline. Hyper-kyphotic AIS patients had a correction of their hyper-kyphosis from $46.5^{\circ} \pm 4.2^{\circ}$ to $36.4^{\circ} \pm 4.6^{\circ}(p=0.003)$ whereas AIS patients that were hypo- or normo-kyphotic at baseline did not have any statistically significant changes in these sagittal alignment parameters. Similarly, when performing a subanalysis of the Lenke type 1 patients and comparing preoperative to postoperative radiographic outcome measures, we noted no statistically significant changes in any measurements with the exception of the main thoracic coronal Cobb angle. Given that our perioperative thoracic Cobb angle correction was mean of $81 \%$, preservation of normal age-adjusted sagittal alignment was achieved.

The cause for the discrepancies in the past regarding sagittal plane parameters is often attributed to the type of constructs used to correct the deformity. Ries et al. [21] noted that in the recent literature, cohorts treated with thoracic pedicle screw constructs often presented with decreased TK, while those treated with hook constructs had increased TK. In the current study, we used cobaltchromium rods and direct sequential vertebral reduction technique for a pedicle screw construct, but did not see a similar decrease in TK in our normo-kyphotic or hypokyphotic patients. Individual surgical techniques and the composition of the implants should be further investigated as explanations for the noted inconsistencies. Finally, while it is generally accepted that increasing the positive 
sagittal balance will result in poorer outcomes, there has not been sufficient evidence suggesting that correcting previously existing thoracic hypo-kyphosis improves clinical outcomes. Glassman et al. [29] came to the conclusion that there is no clinical difference in baseline outcome scores between Lenke type 1 AIS patients with hypokyphosis and normal sagittal alignment 2 years postoperatively. While the research was limited to one subset of AIS, it blends well with the results from our study to question the role of focusing on TK and sagittal alignment as a clinically worthwhile endeavor and use of resources.

There are limitations to our study that need to be considered when applying our results. Firstly, our study was a retrospective review of patients. Secondly, our sample size, though enough to achieve statistically significant results, was limited to 38 patients. Finally, we looked at a diversity of AIS curves and variables which could have caused a Bonferroni effect. A prospective analysis of postoperative AIS sagittal alignment in a larger cohort of patients may better identify perioperative alignment changes for different curve types.

\section{Conclusions}

In conclusion, postoperative AIS patients have comparable sagittal spinopelvic alignment to asymptomatic adolescents without spinal pathology. With due attention to triplanar correction techniques, adequate surgical correction of the coronal plane deformity is possible while maintaining normal sagittal alignment.

\section{Conflict of Interest}

No potential conflict of interest relevant to this article was reported.

\section{References}

1. Wajchenberg M, Astur N, Kanas M, Martins DE. Adolescent idiopathic scoliosis: current concepts on neurological and muscular etiologies. Scoliosis Spinal Disord 2016;11:4.

2. Lafage V, Ames C, Schwab F, et al. Changes in thoracic kyphosis negatively impact sagittal alignment after lumbar pedicle subtraction osteotomy: a comprehensive radiographic analysis. Spine (Phila Pa 1976) 2012;37:E180-7.
3. Lafage V, Smith JS, Bess S, et al. Sagittal spino-pelvic alignment failures following three column thoracic osteotomy for adult spinal deformity. Eur Spine J 2012;21:698-704.

4. Schwab FJ, Blondel B, Bess S, et al. Radiographical spinopelvic parameters and disability in the setting of adult spinal deformity: a prospective multicenter analysis. Spine (Phila Pa 1976) 2013;38:E803-12.

5. Klineberg E, Schwab F, Smith JS, Gupta MC, Lafage V, Bess S. Sagittal spinal pelvic alignment. Neurosurg Clin N Am 2013;24:157-62.

6. de Jonge T, Dubousset JF, Illes T. Sagittal plane correction in idiopathic scoliosis. Spine (Phila Pa 1976) 2002;27:754-60.

7. Hayashi K, Upasani VV, Pawelek JB, et al. Threedimensional analysis of thoracic apical sagittal alignment in adolescent idiopathic scoliosis. Spine (Phila Pa 1976) 2009;34:792-7.

8. Mac-Thiong JM, Roussouly P, Berthonnaud E, Guigui P. Age- and sex-related variations in sagittal sacropelvic morphology and balance in asymptomatic adults. Eur Spine J 2011;20 Suppl 5:572-7.

9. Lowenstein JE, Matsumoto H, Vitale MG, et al. Coronal and sagittal plane correction in adolescent idiopathic scoliosis: a comparison between all pedicle screw versus hybrid thoracic hook lumbar screw constructs. Spine (Phila Pa 1976) 2007;32:448-52.

10. Kim YJ, Lenke LG, Kim J, et al. Comparative analysis of pedicle screw versus hybrid instrumentation in posterior spinal fusion of adolescent idiopathic scoliosis. Spine (Phila Pa 1976) 2006;31:291-8.

11. Lonner BS, Lazar-Antman MA, Sponseller PD, et al. Multivariate analysis of factors associated with kyphosis maintenance in adolescent idiopathic scoliosis. Spine (Phila Pa 1976) 2012;37:1297-302.

12. Kim YJ, Lenke LG, Bridwell KH, et al. Proximal junctional kyphosis in adolescent idiopathic scoliosis after 3 different types of posterior segmental spinal instrumentation and fusions: incidence and risk factor analysis of 410 cases. Spine (Phila Pa 1976) 2007;32:2731-8.

13. Takayama K, Nakamura H, Matsuda H. Low back pain in patients treated surgically for scoliosis: longer than sixteen-year follow-up. Spine (Phila Pa 1976) 2009;34:2198-204.

14. Chang MS, Bridwell KH, Lenke LG, et al. Predicting the outcome of selective thoracic fusion in false dou- 
ble major lumbar "C" cases with five- to twenty-fouryear follow-up. Spine (Phila Pa 1976) 2010;35:212833.

15. Dimeglio A, Bonnel F, Canavese F. Normal growth of the spine and thorax. In: Akbarnia BA, Yazici M, Thompson GH, editors. The growing spine: management of spinal disorders in young children. Berlin: Springer; 2010. p.13-42.

16. Vedantam R, Lenke LG, Keeney JA, Bridwell KH. Comparison of standing sagittal spinal alignment in asymptomatic adolescents and adults. Spine (Phila Pa 1976) 1998;23:211-5.

17. Ghandhari H, Hesarikia H, Ameri E, Noori A. Assessment of normal sagittal alignment of the spine and pelvis in children and adolescents. Biomed Res Int 2013;2013:842624.

18. Mac-Thiong JM, Berthonnaud E, Dimar JR 2nd, Betz RR, Labelle H. Sagittal alignment of the spine and pelvis during growth. Spine (Phila Pa 1976) 2004;29:1642-7.

19. Gutman G, Labelle H, Barchi S, Roussouly P, Berthonnaud E, Mac-Thiong JM. Normal sagittal parameters of global spinal balance in children and adolescents: a prospective study of 646 asymptomatic subjects. Eur Spine J 2016;25:3650-7.

20. Ito M, Abumi K, Kotani Y, et al. Simultaneous double-rod rotation technique in posterior instrumentation surgery for correction of adolescent idiopathic scoliosis. J Neurosurg Spine 2010;12:293-300.

21. Ries Z, Harpole B, Graves C, et al. Selective thoracic fusion of Lenke I and II curves affects sagittal profiles but not sagittal or spinopelvic alignment: a case- control study. Spine (Phila Pa 1976) 2015;40:926-34.

22. Butterworth JF, Mackey DC, Wasnick JD. Morgan and Mikhail's clinical anesthesiology. 5th ed. New York: McGraw-Hill Medical; 2013.

23. Cheng JC, Castelein RM, Chu WC, et al. Adolescent idiopathic scoliosis. Nat Rev Dis Primers 2015;1:15030.

24. Pizones J, Nunez-Medina A, Sanchez-Mariscal F, Zuniga L, Izquierdo E. Thoracic sagittal plane variations between patients with thoracic adolescent idiopathic scoliosis and healthy adolescents. Eur Spine J 2016;25:3095-103.

25. Sangole AP, Aubin CE, Labelle H, et al. Three-dimensional classification of thoracic scoliotic curves. Spine (Phila Pa 1976) 2009;34:91-9.

26. Roussouly P, Labelle H, Rouissi J, Bodin A. Pre- and post-operative sagittal balance in idiopathic scoliosis: a comparison over the ages of two cohorts of 132 adolescents and 52 adults. Eur Spine J 2013;22 Suppl 2:S203-15.

27. Sudo H, Ito M, Abe Y, et al. Surgical treatment of Lenke 1 thoracic adolescent idiopathic scoliosis with maintenance of kyphosis using the simultaneous double-rod rotation technique. Spine (Phila Pa 1976) 2014;39:1163-9.

28. Hilibrand AS, Tannenbaum DA, Graziano GP, Loder RT, Hensinger RN. The sagittal alignment of the cervical spine in adolescent idiopathic scoliosis. J Pediatr Orthop 1995;15:627-32.

29. Glassman SD, Sucato DJ, Carreon LY, Sanders JO, Vitale MG, Lenke LG. Does thoracic hypokyphosis matter in Lenke type 1 adolescent idiopathic scoliosis? Spine Deform 2013;1:40-5. 